\title{
ULTRASTRUCTURAL STUDIES OF THE RABBIT PLACENTA IN THE LAST THIRD OF GESTATION
}

\author{
GAROLE A. SAMUEL, P. M. B. JAGK* AND \\ P. W. NATHANIELSZ* \\ Departments of Anatomy and *Physiology, \\ University of Cambridge
}

(Received 29th November 1974)

\begin{abstract}
Summary. Placental attachment and the ultrastructure of the decidua and placental labyrinth have been studied in rabbits during the final third of gestation. The placenta became progressively easier to separate from the uterine wall as gestation proceeded. This ease of separation was associated with degenerative changes in the decidual tissue, but disruption of the placental labyrinth was not observed until the last $24 \mathrm{hr}$ of pregnancy. Two types of decidual cells were observed; smaller uninucleate glycogen-containing cells and larger multinucleate cells with lipid inclusions. The ageing placentae exhibited increasing decidual degeneration associated with deposition of extracellular fibrous materials. Glycogen became less widely distributed over the period of study and changed from the $\beta$ - to the $\alpha$-configuration. In contrast to the observed disruption of the decidual tissue, the placental labyrinth maintained its integrity until the final stages of pregnancy. A dramatic increase in subcellular activity was observed in the syncytiotrophoblast after 28 days of gestation.
\end{abstract}

\section{INTRODUCTION}

In the last third of pregnancy, the discoidal chorioallantoic placenta of the rabbit consists of two different components: the placental labyrinth, in which fetal tissues are in direct contact with maternal blood, and the decidua, which lies between the placental labyrinth and the uterine wall. After parturition the labyrinthine and decidual components of the placenta are expelled together from the uterus. Each placental disc is detached at the boundary between the decidua and a thin layer of undecidualized stroma which remains adherent to the myometrium. The boundary is usually described as the 'zone of separation' (Amoroso, 1952).

Previous reports of the fine structure of the placental labyrinth include those of Larsen (1962) and Enders (1965). It was established by Enders that two layers of trophoblast are normally interposed between fetal and maternal circulations in the mature placenta. The placenta of the rabbit may thus be described as haemodichorial in type.

According to previous authors the decidua consists of uninucleate and giant 
cells embedded in a matrix of collagen and other fibrous materials. There is no consensus on the origin of multinucleate giant cells, for Mossman (1937) suggested that they could be derived from the uninucleate cells of the decidua, while Larsen (1963) favoured a trophoblastic origin. Uninucleate cells have been shown to be derived from the perivascular cells of the endometrial vessels (Larsen, 1963).

Despite these previous studies the ultrastructural organization of the rabbit placenta in the later stages of pregnancy is largely unexplored. The object of this study was to obtain information on the placenta during the later stages of gestation, and to trace sequential changes in fetal and maternal tissues. Special attention was directed towards those changes which might have significance in the events preceding parturition.

\section{MATERIALS AND METHODS}

\section{Animals}

New Zealand White rabbits were used. They were allowed free access to food and water at all times. Gestational ages were calculated from the time of observed mating (Day 1). Pregnancy was confirmed by abdominal palpation on Day 18.

Placentae were examined from animals of 23, 26, 28, 29, 30 and 31 days gestational age. Four placentae from each of two pregnant does were studied at each stage of pregnancy. In connection with other studies, catheters were inserted in all the animals as previously described (Nathanielsz \& Abel, 1973) so that the catheter tips lay in the dorsal aorta and inferior vena cava above the origin of the uterine vessels. Saline was infused intra-aortically for at least 2 days before tissue collection.

\section{Tissue collection and processing}

Does were anaesthetized with chloroform and the abdominal contents were exposed by a mid-line incision. The uterus was opened along the anti-mesometrial border and the fetuses removed leaving the placentae undisturbed. Segments of the uterine wall with their attached placentae were excised and trimmed close to the placental disc. The disc was then placed uterine side down on a piece of dental wax and cut vertically into two parts. The outer regions of the disc were then trimmed away and strips 4 to $6 \mathrm{~mm}^{2}$ cut through the whole thickness of the disc. These were fixed by immersion for $1 \mathrm{hr}$ at room temperature $\left(22^{\circ} \mathrm{C}\right)$ to allow some hardening of the tissue. Pieces $\left(1\right.$ to $\left.2 \mathrm{~mm}^{3}\right)$ of the placental labyrinth and decidua were then cut and fixed for a further hour in the primary fixative ( $4 \%$ glutaraldehyde variously buffered to $\mathrm{pH} 7 \cdot 4$ with $0 \cdot 1$ M-phosphate, $0.15 \mathrm{M}$-sodium cacodylate or $0.2 \mathrm{M}$-S-collidine). The tissues were then washed in the appropriate buffer and post-fixed in $1 \%$ osmium tetroxide, buffered as the primary fixative, for $2 \mathrm{hr}$ at room temperature. Tissues were dehydrated in a graded series of ethanol. After passage through propylene oxide they were embedded in Araldite (CIBA) which was polymerized at $60^{\circ} \mathrm{C}$ for 36 hr.

Thick sections ( 1 to $2 \mu \mathrm{m}$ ) were cut with glass knives on a Reichert Ultratome 
and stained with $1 \%$ methylene blue $1 \%$ azure II in $1 \%$ borax for preliminary tissue identification with the light microscope. Thin sections ( 500 to $750 \mathrm{~nm}$ ) were cut and mounted on copper grids and stained sequentially with uranyl acetate and lead citrate for observation in a Philips 300 or AEI 6B electron microscope.

\section{RESULTS}

Macroscopic observations

At 23 days of gestation the decidual tissue was firmly attached to both the placental labyrinth and the uterine wall, and when seen in transverse section made up more than half of the thickness of the placental disc (Text-fig. Ia). As gestation proceeded the thickness of the decidual portion of the disc decreased until at 30 days it consisted of only a thin layer (Text-fig. 1b). The placental labyrinth, however, had increased in thickness during the same period of time. Attachment between the decidual tissue and the uterine wall became progressively more tenuous as gestation proceeded until spontaneous contractions of the uterine smooth muscle were sufficient to dislodge the placental disc from the underlying tissues after segments of the uterus had been excised.

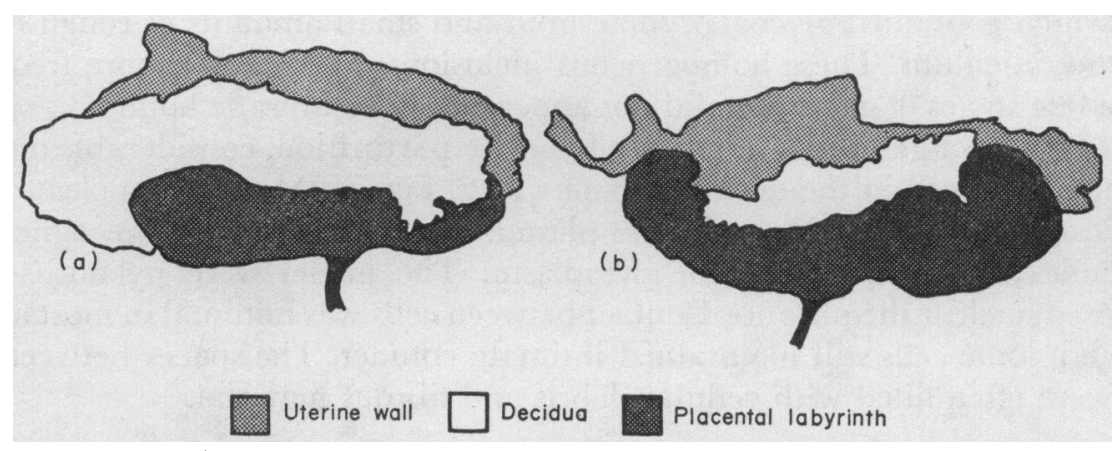

TEXT-FIG. 1. Line drawings taken from photographs of transected placentae from does at (a) 23 days and (b) 30 days of gestation. Drawn to the same scale to illustrate changes in the proportions of decidua and placental labyrinth.

\section{Ultrastructure of the decidua}

Two main types of cells were observed in the decidual portion of the disc; multinucleate giant cells which often contained large amounts of lipid (Pl. 1, Fig. 1), and smaller uninucleate cells which contained glycogen (P1. 1, Fig. 2 and Pl. 2, Fig. 4).

The uninucleate cells of the decidua at 23 and 26 days of gestation (P1. 1, Fig. 2) exhibited close cell-to-cell contact with intimate interdigitation of the plasmalemma (PI. 1, Fig. 3). Mitochondria were present in these cells, but other organelles were sparse. There was a region around the perimeter of the cells which contained microfibrils. Most cells were packed with glycogen granules distributed in the particulate or $\beta$-form (Revel, 1964). Some intercellular fibrous material was present where the cells were not intimately attached.

With increasing gestational age fewer cells contained glycogen. The glycogen, 
which was in the rosette form (Pl. 2, Fig. 4) and more closely packed than at earlier stages, was sometimes accompanied by lipid and electron-dense inclusions. The band of microfibrils was present within the plasmalemma, but the association of individual cells was less intimate than previously.

The multinucleate cells possessed many small lipid droplets (Pl. 1, Fig. 1) which were more common in the later stages of gestation. Many short lengths of rough endoplasmic reticulum and small electron-dense membrane-bound inclusions were present in these cells. The nuclei were clumped together and were irregular in outline with condensed chromatin attached to the nuclear membrane. A peripheral band of microfibrils within the cytoplasm was similar to that found in the glycogen-containing cells. Many small microvilli projected into the intercellular spaces around the perimeter of the multinucleate cells.

In the decidual tissue towards the end of gestation (Days 29, 30 and 31) there was a marked increase in extra-cellular collagen and fibrous materials (Pl. 1, Fig. 2 and Pl. 2, Fig. 5). There was also a breakdown of cell-to-cell contact and in some areas of the decidua there was fragmentation of the cells. This apparent disintegration of parts of the tissue was more common at the later stages. Within the uninucleate cells the distribution of glycogen was more varied and the bands of microfibrils more prominent than at earlier stages.

Extremely electron-dense inclusions were found (Pl. 2, Fig. 6) in uninucleate cells which contained glycogen, some lipid and small amounts of rough endoplasmic reticulum. These homogeneous inclusions, which were more frequent in the late stages of gestation, did not appear to be membrane bound.

On Day 31 of gestation, immediately before parturition, considerable disruption was observed in the decidual tissue (Pl. 2, Fig. 7). Many uninucleate cells were fragmented with discontinuous plasma membranes and few recognizable organelles remained within the cytoplasm. The nuclei were pyknotic with shattered nuclear membranes. Contact between cells was minimal in most areas, although some cells still maintained intimate contact. The spaces between the cells were often filled with cellular debris and fibrous material.

\section{Ultrastructure of the placental labyrinth}

Plate 3, Fig. 8 illustrates the relationship between fetal and maternal tissues at 26 days of gestation. The fetal vessels were enclosed by a thin electron-dense endothelium which was formed of overlapping cells containing many cytoplasmic granules. In places, two basal laminae were present representing one lamina attached to the vessel and one attached to the cytotrophoblast. Where the vessel was closely apposed to the cytotrophoblast, only one lamina was visible. The cytotrophoblast was also extremely electron-dense and presented numerous short projections into the space between it and the syncytium. The

\section{EXPLANATION OF PLATES 1 TO 3}

Sections of rabbit placenta in the last third of pregnancy. Abbreviations: bl, basal lamina; coll, collagen; CT, cytotrophoblast; F, fibrous material; FEn, fetal endothelium; FV, fetal vessel; G, glycogen; Go, Golgi apparatus; ICS, intercellular space; L, lipid droplets; $\mathrm{m}$, mitochondria; MBS, maternal blood space; mf, microfibrils; mv, microvilli; $\mathrm{pN}$, pyknotic nucleus; rer, rough endoplasmic reticulum; ser, smooth endoplasmic reticulum; ST, syncytiotrophoblast. 

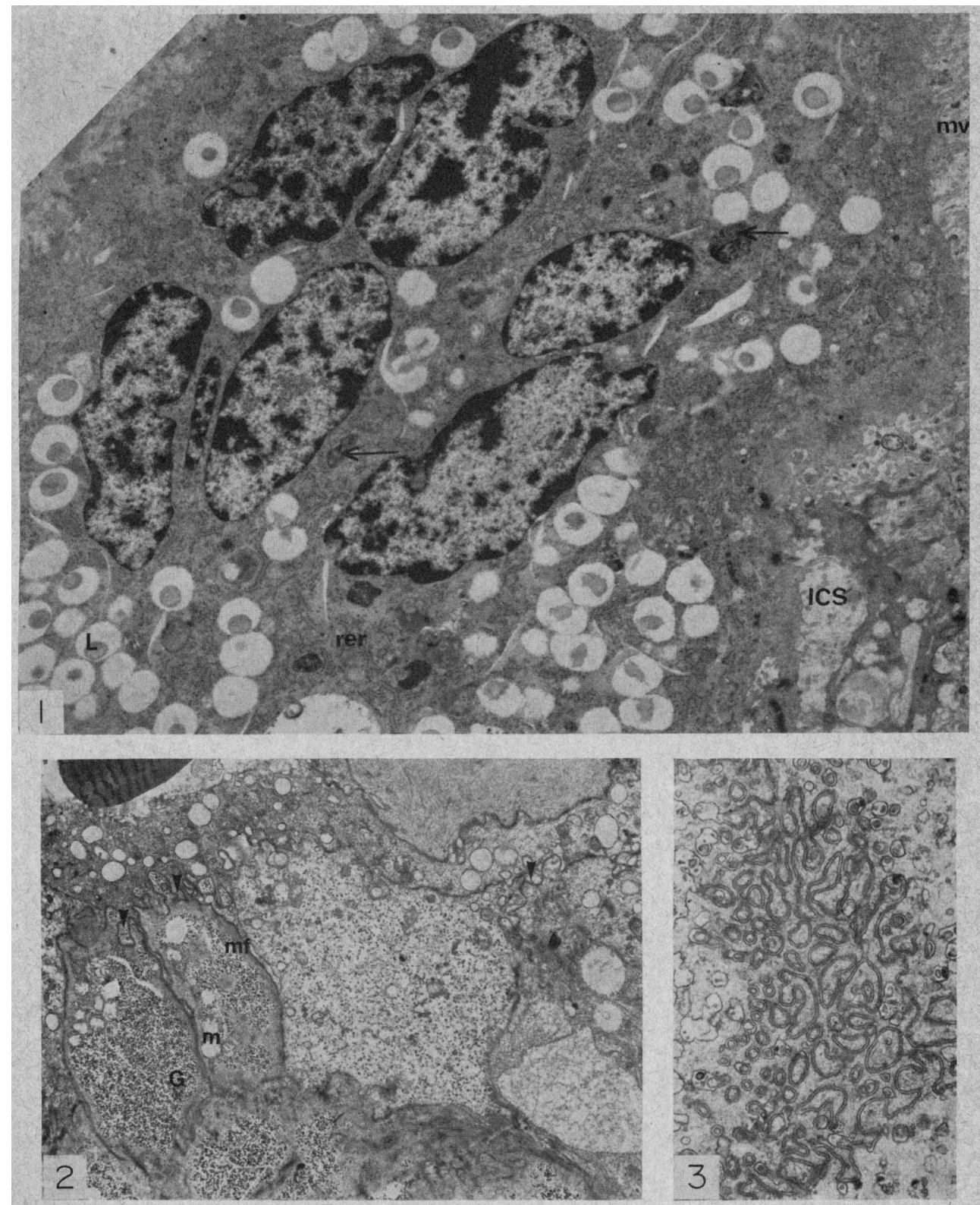

Fiti. 1. Multinucleate giant cell found in the decidua on Day 28. $\times 800$.

Fic. 2. Uninucleate decidual cells containing glycogen on Day $23 . \times 2050$.

Fic. 3. Complex interdigitations of the plasma membranes between uninucleate decidual cells. $\times 4500$.

(Iacing p. 12) 
PLATE 2

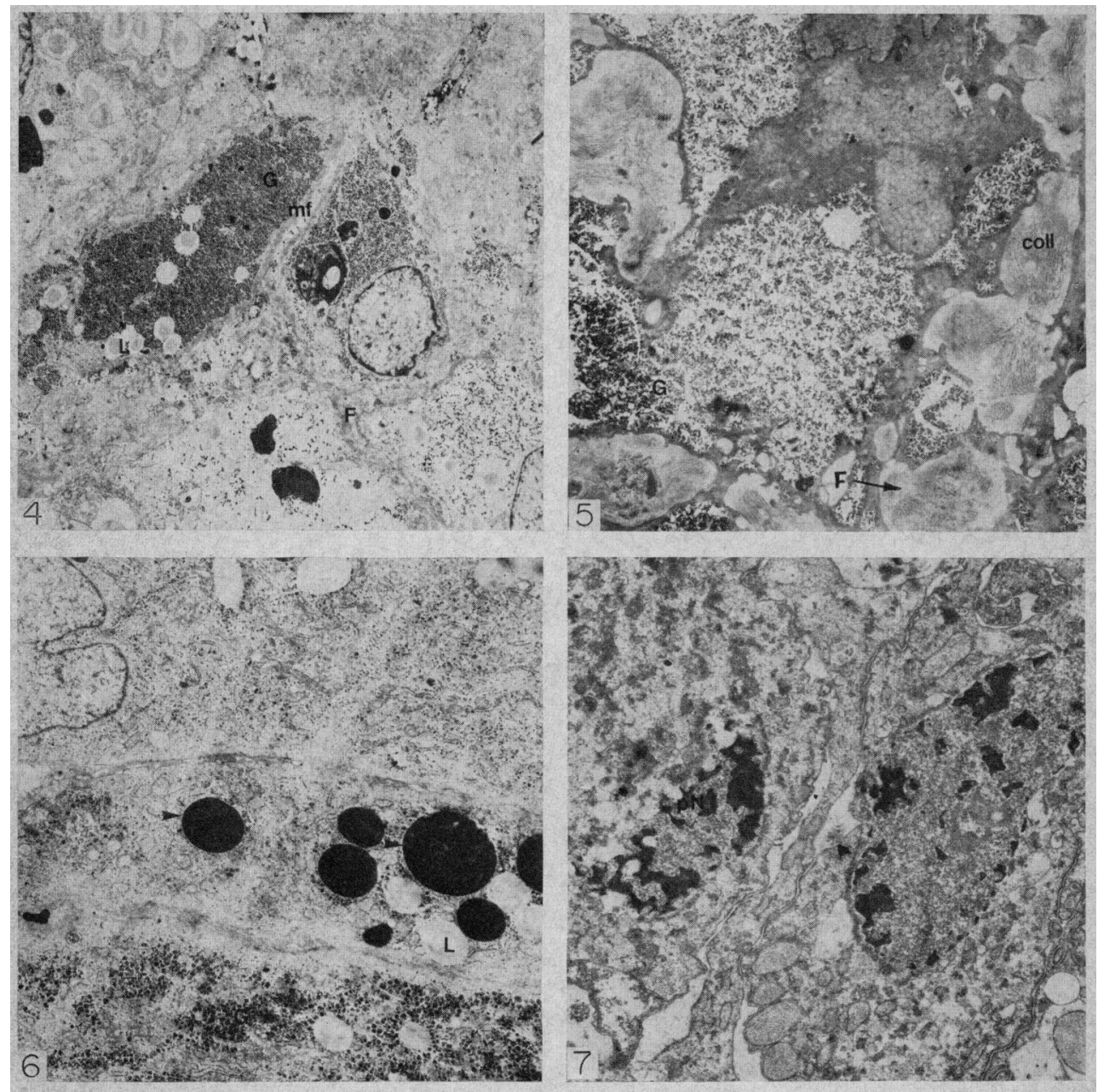

FIG. 4. Glycogen-containing decidual cells on Day 28. $\times 1400$.

Fig. 5. Uninucleate decidual cells on Day 28 showing increased deposition of fibrous material around the cells. $\times 2000$.

FIg. 6. Uninucleate decidual cells on Day 31 showing large membrane-free electrondense inclusions (arrows). $\times 2750$.

Fig. 7. Uninucleate decidual cells on Day 31 showing advanced state of degeneration. $\times 3500$. 
PLATE 3
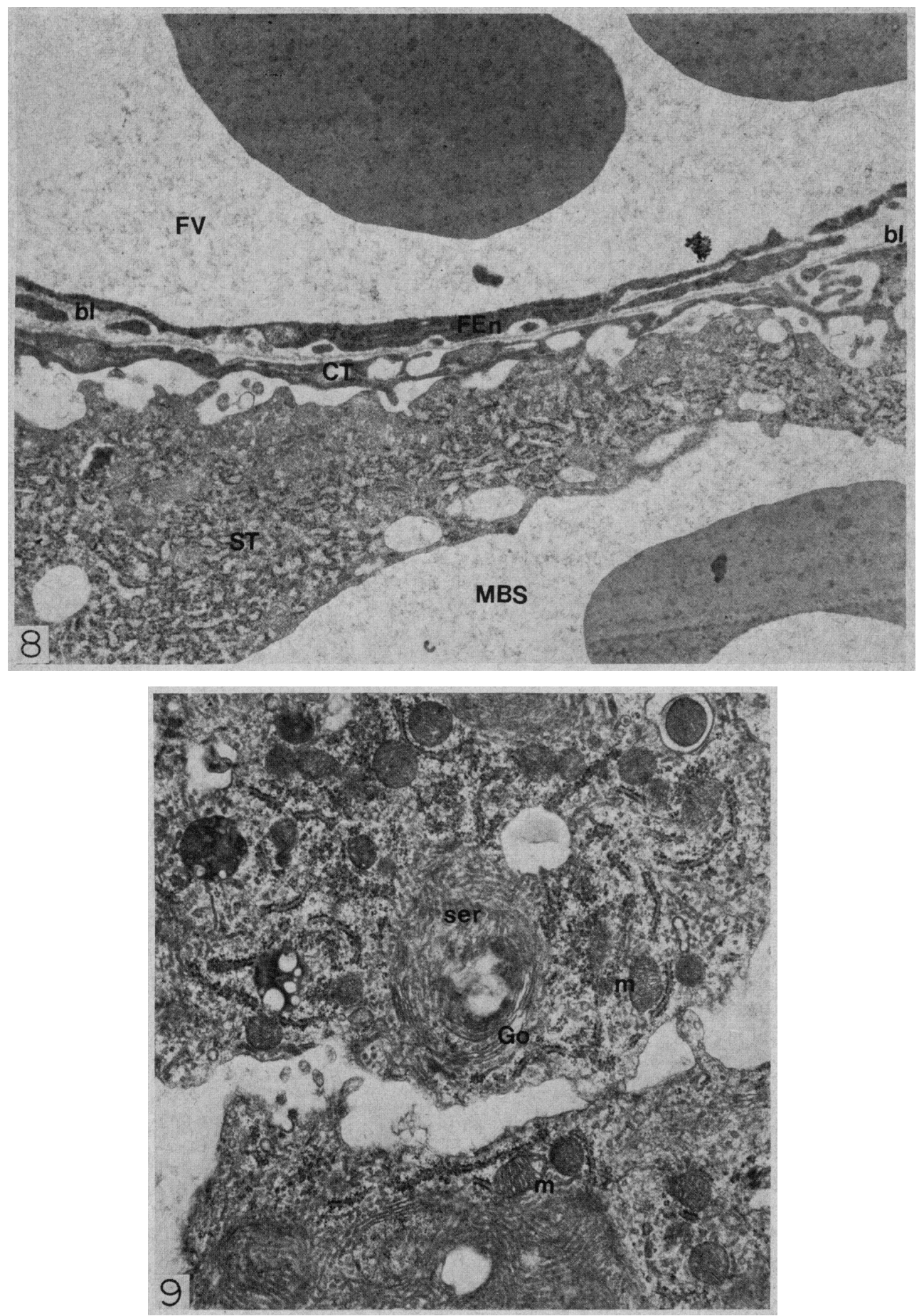

Fig. 8. Placental labyrinth on Day 26. $\times 8800$.

Fis. 9. Syncytiotrophoblast on Day 28. $\times 11,000$. 
syncytium consisted of large sheets of tissue of varying thickness and containing many short lengths of rough endoplasmic reticulum. Projections from the syncytium into the maternal blood space were short and often reflexed into the tissue.

There was little ultrastructural difference between the placental labyrinths examined at 23, 26, and 28 days. After this time, however, an extensive proliferation of whorls of smooth endoplasmic reticulum was observed in the syncytiotrophoblast (P1. 3, Fig. 9). This was associated in many cases with enlargement of the Golgi apparatus, an increase in the numbers of mitochondria and the presence of membrane-bound inclusions. The rough endoplasmic reticulum was also more extensive, and its lumen was filled with an electron-dense substance. This development continued until immediately before parturition when large vacuoles and lipid droplets appeared in the syncytium. At this stage the cytotrophoblast no longer maintained a complete barrier between the syncytium and the endothelium of the fetal capillaries.

\section{DISGUSSION}

Artificial separation of the disc of the rabbit placenta becomes increasingly easier as gestation proceeds, and by Day 31 very little mechanical force is needed to dislodge the placenta from excised segments of the uterine wall. From Days 23 to 31 the decidua becomes progressively thinner. At the same time, the placental labyrinth appears to increase in size, so that the overall thickness of the disc remains relatively constant.

Larsen (1963), in his study of the decidua from 8 to 29 days of gestation, concluded that degeneration of the decidua before parturition was limited to the zone of separation. He noted that this zone consisted largely of debris from multinucleate giant cells, with a smaller contribution from the uninucleate cells of the decidua. If the loss of close cell contact and the deposition of fibrous material in the intercellular spaces can be interpreted as evidence of degenerative change, then our results show that from Day 29 onwards such changes occur to various degrees throughout the decidua. It is not until Day 31, however, that the majority of decidual cells begin to show obvious signs of breakdown and fragmentation, and even at this stage the decidual component of the placental disc remains firmly adherent to the placental labyrinth.

Our observations on the ultrastructural organization of the decidua have confirmed the reports of previous authors that uninucleate and giant cells are the two main components of this tissue. We have found, however, that glycogen is located mainly in the uninucleate decidual cells, where its structure changes with increasing gestational age. The observation that glycogen changes its character and distribution over the period of investigation correlates with the timing of the decline in total glycogen content reported by Jost (1954). Multinucleate giant cells, on the other hand, contain lipid inclusions and many short lengths of rough endoplasmic reticulum. It is difficult to reconcile these findings with those of Mossman (1937), who described the uninucleate cells as 'true decidua' and the multinucleate cells as 'glycogen storers'. Neither have we found evidence to support the opinion that multinucleate cells are trophoblastic in 
origin (Larsen, 1963). Since collagen and other fibrous material appears to be secreted by the decidua, and since only the multinucleate cells contain rough endoplasmic reticulum to any significant extent, it is suggested that decidual giant cells are mesodermal in character and therefore probably of maternal origin.

Studies of maternal blood flow to the uterus of rabbits at 27 to 29 days of gestation have shown that the placentae receive about $67 \%$ of the total uterine blood flow (Duncan, 1969), and that absolute blood flow to the placenta increases to the time of parturition (Leduc, 1972). The finding of Leduc is consistent with the increasing extent of the labyrinth as gestation proceeds. It seems, therefore, that the supply to the maternal blood spaces of the placental labyrinth is not adversely affected by the structural changes in the decidual tissue, although the supply to the decidua itself may possibly be restricted by the occlusion of some of the smaller maternal vascular pathways. Such occlusion could explain the patchy distribution of the degenerative changes seen in the decidua on Days 29 to 30 , but seems unlikely to be the sole cause of the more widespread breakdown of the decidua on Day 31.

Changes in the activity of decidual and trophoblastic tissue, as indicated by increases in smooth endoplasmic reticulum, electron-dense inclusions and the deposition of lipid, may be important in the production of hormones required for the normal maintenance of pregnancy or events associated with the initiation of parturition.

\section{ACKNOWLEDGMENTS}

The authors wish to acknowledge the able assistance of numerous members of staff of the Departments of Anatomy and Physiology, University of Cambridge. We would like to thank Mr D. H. Steven for his helpful discussion and encouragement. This work was supported by the Lalor Foundation. One of us (G.A.S.) is a Medical Research Council Junior Research Fellow.

\section{REFERENCES}

Amoroso, E.C. (1952) Placentation. In Marshall's Physiology of Reproduction, vol. 2, chap. 15, pp. 127-311. Ed. A. S. Parkes. Longmans, Green and Co. Ltd, London.

Duncan, S.L.B. (1969) The partition of uterine blood flow in the pregnant rabbit. F. Physiol., Lond. $204,421-433$.

ENDERs, A.C. (1965) A comparative study of the fine structure of the trophoblast in several haemochorial placentae. Am. F. Anat. 116, $29-67$.

Jost, A. (1954) Hormonal factors in the development of the fetus. Cold Spring Harb. Symp. quant. Biol. $19,167-181$.

LARSEN, J.F. (1962) Electronmicroscopy of the chorioallantoic placenta of the rabbit. I. The placental labyrinth and the multinucleated giant cells of the intermediate zone. F. Ultrastruct. Res. 7, 535549.

LARSEN, J.F. (1963) Electronmicroscopy of the chorioallantoic placenta of the rabbit. II. The decidua and the maternal vessels. $\mathcal{F}$. Ultrastruct. Res. 8, 327-338.

LEDUC, B. (1972) Maternal placental blood flow and gestational age. Am. F. Obstet. Gynec. 112, 374-378.

Mossman, H.W. (1937) Comparative morphogenesis of the fetal membranes and accessory uterine structures. Contrib. Embryol. 26, 129-246.

Nathanielsz, P.W. \& Abel, M.A. (1973) Initiation of parturition in the rabbit by maternal and foetal administration of cortisol: effect of rate and duration of administration; suppression of delivery by progesterone. 7 . Endocr. 57, 47-54.

ReVEe, J.P. (1964) Electronmicroscopy of glycogen. F. Histochem. Cytochem. 12, 104-114. 